\title{
Gecikmiş Bir Tanı:
}

\section{Mukozal Tutulumla Seyreden Pemfigus Vulgaris}

\section{A Delayed Diagnosis: Pemphigus Vulgaris With Mucosal Involvement}

\author{
Serap Güneş Bilgili', Zehra Kurdoğlu², Ayşe Serap Karadağ' ${ }^{1}$, Gülay Bulut ${ }^{3}$ \\ 'Yüzüncü Yıl Üniversitesi, Dermatoloji Ana Bilim Dalı, Van

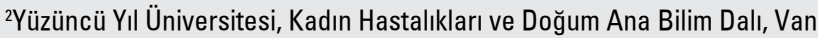 \\ ${ }^{3}$ Van Yüksek İhtisas Eğitim ve Araştırma Hastanesi, Patoloji Bölümü, Van
}

\section{Özet}

Pemfigus vulgaris derive mukozaları tutan, vezikül ve büllerle karakterize, kronik, otoimmün bir hastalıktır. Sıklıkla oral mukozada başlayıp deriye ve diğer mukozal bölgelere yayılım gösterir. Pemfigus vulgariste genital mukoza tutulumu daha nadir görülmektedir. Deri tutulumunun olmadığı durumlarda tanı koymak güç olabilmektedir. Yirmi yıldır oral mukozada, 10 yıldır genital bölgede erozyon ve ülserasyonları olan 46 yaşındaki bayan hastaya, klinik ve histopatolojik değerlendirme sonucu pemfigus vulgaris tanısı konuldu. Bu olgu, histopatolojik inceleme ile tanısı kolayca doğrulanabilen pemfigus vulgarisin, tedaviye yanıt vermeyen oral ve genital ülserlerin ayırıcı tanısında akılda tutulması gerektiğini vurgulamak amacı ile sunulmaktadır.

Anahtar Kelimeler: Pemfigus vulgaris; genital ülser; mukoza tutulumu.

Başvuru Tarihi: 24.05.2011 Kabul Tarihi: 08.07.2011

\section{Giriş}

Pemfigus vulgaris deri ve müköz membranların yaşamı tehdit edici, kronik seyirli, otoimmün büllöz hastalığıdır. Akdeniz havzasında ve Yahudilerde daha sık görülen hastalığın dünyadaki yıllık insidansı milyonda 0.76-9.3 arasında değişmektedir. ${ }^{1,2}$ Erkek ve kadınlar eşit sıklıkta etkilenmektedir. ${ }^{3}$ Pemfigus vulgariste mukozal lezyonların deri lezyonlarından önce başlama sıklığı \%48-70 oranındadır. Fakat hastaların \%90'ından daha fazlasında mukozal lezyon görülür ve en sık oral mukoza tutulumu

\begin{abstract}
Pemphigus vulgaris is a chronic autoimmune disease characterized by blistering of the skin and mucosa. Most commonly, the disease begins in the oral mucosa and spreads to the other mucous membranes and skin. The frequency of genital tract involvement in pemphigus vulgaris is rare. When the skin is not involved, the diagnosis may be difficult. After clinical and histopathologic examinations, pemphigus vulgaris was diagnosed at a 46 year old woman who had erosion and ulseration in oral mucosa for 20 years and in genital region for 10 years This case was presented to emphasize that pemphigus vulgaris which may be confirmed easily by histopathologic examination should be kept in mind in the differential diagnosis of oral and genital ulcers which do not respond to treatment.
\end{abstract}

Keywords: Pemphigus vulgaris; genital ulcer; mucosal involvement.

Aplication: 24.05.2011 Accepted: 08.07.2011

olur. ${ }^{4,5}$ Pemfigus vulgariste vulva, vajina ve serviks de dahil olmak üzere genital bölge tutulumları da bildirilmiştir. Genital mukoza tutulumu deri ve oral mukoza tutulumu ile eş zamanlı olabileceği gibi tek başına da olabilir. ${ }^{6,7}$ Deri tutulumu olmaksızın oral ve genital mukoza tutulumu ile seyreden pemfigus vulgarisli olgu, nadir görülmesi ve uzun süre tanı konulamaması nedeni ile sunulmaktadır.

\section{Olgu}

Kırkaltı yaşında bayan hasta oral ve genital mukozada 
yara şikayeti ile polikliniğimize başvurdu. Hikayesinden 20 yıldır ağzında, son 10 yıldır ise genital bölgesinde yaralar oluştuğu öğrenildi. Bu şikayetlerle pek çok kez doktora başvuran hastaya Behçet hastalığı tanısı ile sistemik kolşisin ve prednizolon tedavilerini verilmişti. Bu ilaçları düzensiz olarak kullanan hasta şikayetlerinin prednizolon aldığı dönemlerde azaldığını, ilacı bırakınca tekrar devam ettiğini ifade etti. Dermatolojik muayenesinde, klitoriste ve labium minörlerin birleşim komissüründe yer yer erode olmuş beyaz renkli plaklar (Resim 1) ile sert ve yumuşak damakta, her iki bukkal mukozada ve alt diş gingivalarında yer yer erode plaklar vardı. Hastanın smear sonucu inflamasyon ve atrofi dışında normal olarak rapor edildi. Behçet hastalığına yönelik olarak yapılan paterji testi negatif olarak değerlendirildi. Bilgilendirilmiş onam formu alınan hastanın klitorisinden pemfigus vulgaris ön tanısı ile perilezyonel olarak deri biyopsisi alındı. Histopatolojik incelemede epidermiste suprabazal ayrışma ve akantolizis saptandı (Resim 2). Direkt immünfloresan incelemede ise epidermiste interselüler lgG birikimi saptanarak pemfigus vulgaris ile uyumlu olarak değerlendirildi (Resim 3). Hastaya sistemik tedavi olarak $60 \mathrm{mg} / g u ̈ n$ prednisolone tb ve genital bölge lezyonları için topikal metilprednisolon aseponat krem 1x1 verildi. Ayrıca steroidden koruyucu olarak Ca efervesan kapsül ve lansaprazol kapsül eklendi. Tedavi ile hastanın lezyonları 1 ay sonra gerilemeye başladı ve kontrollü olarak steroid dozu azaltıldı. Hasta halen takibimiz altındadır.

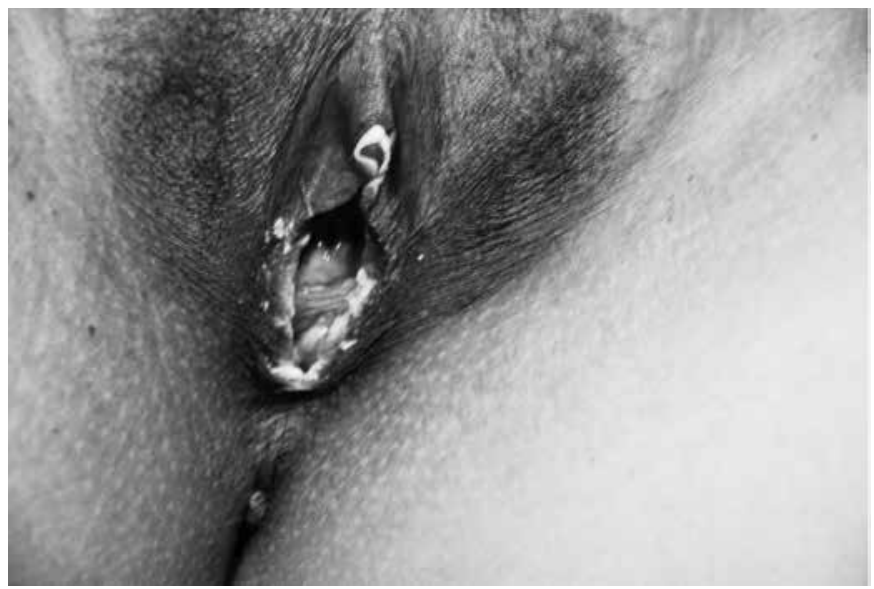

Resim 1: Klitoriste ve labium minorlerin birleşim komissüründe yer yer erode olmuş beyaz renkli plaklar.

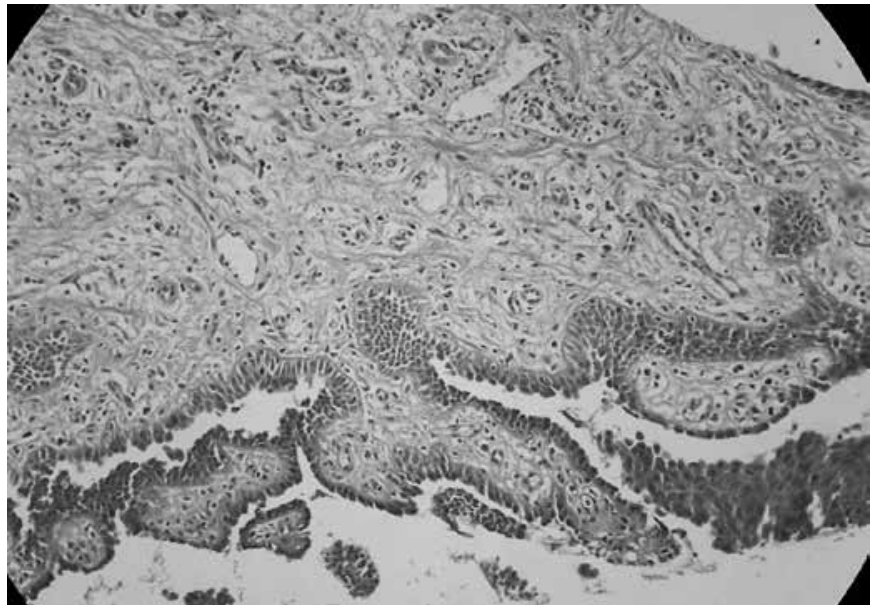

Resim 2: Epidermiste suprabazal ayrışma ve akantolizis (Hematoksilen-eozin $\times 100$ ).

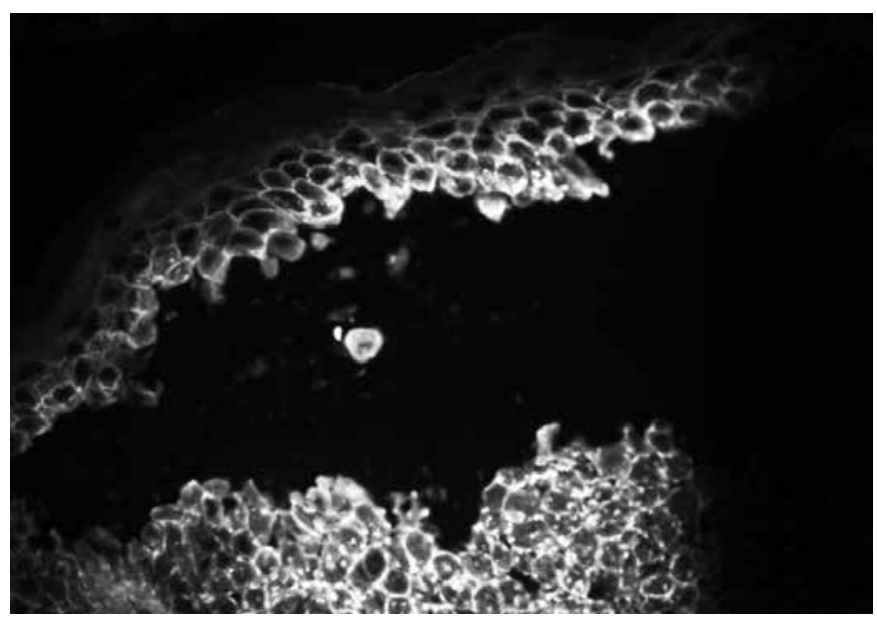

Resim 2: Epidermiste suprabazal ayrışma ve akantolizis (Hematoksilen-eozin x 100)

\section{Tartıșma}

Pemfigus vulgaris deri ve mukozayı tutan akantolitik suprabazal vezikül ve bül oluşumu ile karakterize otoimmun bir hastalıktır. Sıklıkla oral mukozada ağrılı ülserler şeklinde başlar. Ortalama 4-8 ay içerisinde deride de vezikül ve büller ortaya çıkmaya başlar. Ancak hastaların yaklaşık $\% 5^{\prime}$ inde hastalık oral mukozaya sınırlı kalır ve deride hiç lezyon oluşturmadan erozif deskuamatif gingivostomatit tablosu şeklinde seyreder. ${ }^{1,8}$ Olgumuzda 20 yıldır oral mukozada son 10 yıldır ise genital mukozada ağrıı erozyon ve ülserasyonlar olup deride vezikül ve bül yoktu. 
Deri tutulumu olmamasından dolayı tanı konulma süreci gecikmişti. Pemfigus vulgariste kadın genital mukozası da tutulabilir. Kadın genital mukozasının tutulumu ile ilgili bildiriler sınırlı sayıda olgu sunumu şeklindedir. 7,9,10 Yapılan az sayıdaki çalışmada farkıı tutulum oranları bildirilmiştir. 3,11,12 Marren ve arkadaşları dokuz pemfigus vulgarisli hastanın dördünde vulva tutulumu olduğunu belirtirken ${ }^{11}$ Malik ve Ahmed sadece genital bölge tutulumlu pemfiguslu hastalarla yaptıkları çalışmada pemfigusta genital tutulumun nadir olduğunu ve vajinal lezyonlardan ziyade vulva tutulumunun daha fazla olduğunu bildirmişlerdir. Hastaların \%61'inde labial tutulum, \%30'unda vajinal tutulum, \%3'ünde ise sadece vajinal tutulum saptanmıştır.3 Genital bölge tutulumu nadir olmakla birlikte yapılan bir diğer çalışmada 77 pemfigus vulgarisli hastanın 39'unda (\%51) genital bölge tutulumu tespit edilerek oral mukozadan sonra ikinci en sık tutulan mukozal bölge olduğu öne sürülmüştür. Labia minör tutulumu \%92, labia majör tutulumu \%28, vajinal tutulum \%36 ve serviks tutulumu \%15 olarak tespit edilmiştir. ${ }^{12}$ Hastamızda labium minuslarda tutulum vardı.

Pemfigus vulgaris tanısı klinik muayene, tutulan deriden yapılan biyopsiler sonucu histopatolojik inceleme ve immunolojik bulgular (direkt ve indirekt immünfloresan test) ile konulur. ${ }^{3}$ Histopatolojik olarak akantolitik hücrelerin eşlik ettiği suprabazal ayrışma ve bül görülür. Dokuya fikse otoantikorları göstermeye yönelik olarak direkt immünfloresan test tanıda altın standart kabul edilir ve testin duyarlıı̆̆ı \%90'ın üzerindedir. Tüm epidermis boyunca interselüler aralıkta kesintisiz balık ağı görünümündeki elma yeşili floresan veren depolanma pemfigus için tanı koydurucudur. Depolanan antikor IgG ve/veya C3'tür. ${ }^{1}$ Olgumuzda deri tutulumu olmadığı için tipik vezikül ve büller izlenmemekle birlikte oral ve genital mukozada erozyon ve ülserler tespit edildi. Alınan perilezyonel biyopside pemfigus vulgaris ile uyumlu olarak histopatolojik incelemede; akantoliz, epidermiste suprabazal ayrışma, direkt immünfloresan incelemede yeşil floresan veren balık ağı görünümünde epidermiste interselüler IgG birikimi dikkati çekti.

Tedaviye başlamadan önce uzun süreli ve ciddi komplikasyon gelişme riskinden dolayı pemfigus vulgaris tanısı klinik, histopatolojik ve immünfloresan bulgular ile doğrulanmalıdır. ${ }^{1}$ Tedavide ilk seçenek kortikosteroidlerdir. Başlangıç dozu hastalığın şiddetine göre 1-2 mg/kg/ gündür. Steroid tedavisinin yan etkilerinden korunmak, steroid dozunu hızlı düşürebilmek ve tedavi süresini kısaltabilmek için patojen antikor yapımını baskılayan immünsupresif ilaçlar da steroid tedavisine eklenmektedir. Bu immünsupresifler azathioprine, mikofenolat mofetil, metotreksat, siklosporin ve siklofosfamiddir. Şiddetli ve dirençli pemfigusta, plazmaferez, intravenöz immünglobulin ve immünabsorbsiyon gibi tedavi seçenekleri de mevcuttur. ${ }^{8}$ Olgumuzda sistemik olarak $60 \mathrm{mg} / g u ̈ n$ kortikosteroid ve topikal olarak metilprednisolon aseponat krem 1x1 başlandı. Tedavi ile lezyonlarda belirgin iyileşme saptandı.

Olgumuzda olduğu gibi deri tutulumunun olmadığı durumlarda uzun süre hastaya tanı konulamayabilir. Özellikle tedaviye dirençli genital mukoza erozyonlarında tanıda pemfigus vulgaris düşünülmelidir. Ancak genellikle bu ülserlerin nonspesifik tedaviler ile iyileşme göstermeksizin aylarca sebat etmesinden sonra pemfigus vulgaris tanısı akla gelebilmektedir.

Sonuç olarak, uzun süre iyileşmeden devam eden oral ve genital ülserlerde pemfigus vulgaris tanısı akılda tutulmalıdır. 


\section{Kaynaklar}

1. Uzun S. Pemfigus. Tüzün $Y$, Gürer MA, Serdaroğlu $S$, Oğuz $O$, Aksungur VL, editör. Dermatoloji. 3. Baskı. Istanbul: Nobel Tıp Kitabevleri; 2008. 807-832.

2. Uzun S, Durdu M, Akman A, Gunasti S, Uslular C, Memisoglu HR, et al. Pemphigus in the Mediterranean region of Turkey: a study of 148 cases. Int J Dermatol 2006;45(5):523-528.

3. Malik M, Ahmed AR. Involvement of the female genital tract in pemphigus vulgaris. Obstet Gynecol 2005;106:1005-1012.

4. Metin A, Çalka Ö, Cesur RS. 1994-2000 yılları arasında kliniğimize başvuran pemfigus hastalarının klinik özellikleri. Lepra Mecm 2001; 32: 17-28.

5. Calka O, Akdeniz N, Tuncer I, Metin A, Cesur RS. Oesophageal involvement during attacks in pemphigus vulgaris patients. Clin Exp Dermatol. 2006;31(4):515-519.

6. Chams-Davatchi C, Valikhani M, Daneshpazhooh M, Esmaili N, Balighi K, Hallaji Z, et al. Pemphigus: analysis of 1209 cases. Int J Dermatol 2005;44(6):470-476.

7. Chan E, Thakur A, Farid L, Lessin S, Uberti- Benz M, James W.
Pemphigus vulgaris of the cervix and upper vaginal vault: a cause of atypical Papanicolaou smears. Arch Dermatol 1998; 134:14851486.

8. Küçükoğlu R, BabunaG. Pemfigus-Etiyolojisi, Pemfigus Vulgaris, Pemfigus Vejetans, Paraneoplastik Pemfigus:Klinik ve Tedavi. Turkiye Klinikleri J Dermatol-Special Topics 2008;1(4):16-24.

9. Lonsdale RN, Gibbs S. Pemphigus vulgaris with involvement of the cervix. Br J Dermatol 1998; 138:363-365.

10. Batta K, Munday PE, Tatnall FM. Pemphigus vulgaris localized to the vagina presenting as chronic vaginal discharge. $\mathrm{Br} \mathrm{J}$ Dermatol 1999;140:945-947.

11. Marren P, Wojnarowska F, Venning V, Wilson C, Nayar M. Vulvar involvement in autoimmune bullous diseases. J Reprod Med 1993; 38: 101-107.

12. Akhyani M, Chams-Davatchi C, Naraghi Z, Daneshpazhooh $M$, Toosi S, Asgari $M$, et al. Cervicovaginal involvement in pemphigus vulgaris: a clinical study of 77 cases. $\mathrm{Br} \mathrm{J}$ Dermatol. 2008;158(3):478-482. 